\title{
Terrorism, et al
}

\author{
Marvin L. Birnbaum, MD, PhD
}

Presented 04 September 2003 at the 1st NATO Medical Conference on Civil-Military Co-operation, Ljubljana, Slovenia

Fear is stronger than love.

Thomas Fuller, Gnomologia No. 1513

...international terrorism ... endangers or takes innocent buman lives or jeopardises fundamental freedoms, and the underlying causes of those forms of terrorism and acts of violence ... lie in misery, frustrations, grievance, and despair and ... cause some people to sacrifice human lives, including their own in an attempt to effect radical changes.

UN General Assembly Resolution 3034

This issue and the next issue of Prehospital and Disaster Medicine deal with the prevalence of and issues associated with terrorism from an international perspective. The papers included were collected and edited by Dr. Jeffrey Arnold, who has invested limitless hours in his desire to clarify the issues associated with terrorism. He has worked with each of the authors to provide the clearest possible reports. As a beginning to an ongoing program, he has accumulated reports from 17 countries. These Special Reports provide a remarkable summary of the scope of terrorism worldwide. He puts the entire issue into perspective in his editorial, "The International Burden of Terrorism" In addition, he has promoted the development of consensus for a medical/public health definition of terrorism (pages 47-52). In achieving these landmarks, he continues to provide important leadership in the discipline of Disaster and Emergency Medicine.

Several additional points may help in establishing the language and issues associated with terrorism. First, the terms terrorism, terror, and terrorist as used elsewhere by many have been interchanged inappropriately. Terrorism is an action, terror is the effect intended by acts of terrorism, and a terrorist is the actor. The intent of terrorism is to create change by the creation of fear in a target population in an effort to force economic, political, and/or social change. Since terrorism often is associated with fanaticism for a cause, similar definitions pertain. By definition, a fanatic is a person filled with excessive and often misguided enthusiasm for something. ${ }^{1}$ In the context of terrorism, fanatics are angry persons looking for revenge for some action or rule that they consider inappropriate. The motivation is to create damage and not to create change. The Oklahoma City bombing was an act of fanaticism and not terrorism. Fanaticism is the action-an attempt or attempts to achieve the cause, and a fanatic is the actor attempting to achieve the cause. The net effect of a terrorist act or an act done by a fanatic is damage, which is generally both physical and emotional. Thus, the medical impact of both terrorism and fanaticism is the same. The medical/public health definition of terrorism developed by Dr. Arnold and his colleagues is essential to the development of our science.

As you peruse the country reports, it will become apparent that so far, from a medical/public health perspective, terrorist acts have created multi-casualty incidents, at least from the perspective of physical injuries. Generally, the responses have not required outside medical assistance. Whether such acts have created a sufficient degree of terror and disorganization in the populations affected either directly or indirectly, in order to be labeled as a disaster is not clear. But, what will occur when the production of multi-casualty incidents do not produce the political/economic changes sought by the terrorists? Will the terrorists then resort to creation of larger events that will result in sufficient levels of damage to cause disasters, such as could occur by employing weapons of mass destruction (WMD)? In such circumstances, the objectives of the terrorists would remain the same--creation of fear in the target population(s) and others. But, now outside assistance would be needed to respond to such events and the human toll would escalate.

In order to analyze factors associated with the preparedness and/or response to terrorism, terrorism must be considered as a Hazard! Some would consider the circumstances that result in terrorism as the hazard. Regardless, terrorism must be dealt with as we would any other hazard as described in the Conceptual Framework of the Guidelines. ${ }^{1}$ As with any hazard, interventions can be applied before the hazard becomes an event (pre-event). Such interventions include eliminating of the hazard, modificating of the hazard, decreasing the risk that a hazard will become an event, or by implementating of measures that will enhance the absorbing capacity of the society in case the hazard becomes an event. Augmentation of the absorbing capacity should reduce the amount and severity of the damage resulting from a given terrorist event. Each of these measures is a 
component of preparedness. Similarly, augmentation of the buffering capacity and enhancement of the responses to a terrorist event require other interventions. Discussions of such interventions in the context of terrorism comprise the next issue of this Journal.

As is evident from the articles included in the current issue, most countries are investing considerable amounts of resources in interventions for the "war against terrorism". As such efforts are implemented, some value must be attached to each. Unfortunately, for the most part, such efforts are being implemented without a clear vision of what is to be accomplished. Where is the explicit expression of such an overall vision? What interventions will give us the biggest bang for the buck in reaching the ultimate goal? If the hazard cannot be eliminated, what can the world community do to minimize the risk or the damage? Can individual countries work in isolation, or is terrorism a worldwide hazard? The articles in the present issue seem to attest to the latter.

It is apparent that many of the interventions designed to combat terrorism or the effects of terrorist acts could have more far-reaching benefits when adapted to events other than those related to terrorism. Is the RISK that a terrorist event will produce a massive number of casualties requiring an international response GREATER THAN the RISK associated with any other type of catastrophic event? Is preparedness for a terrorist event resulting in mass casualties different from that for any other catastrophic event? The obvious answer is that it is most prudent that we take an ALL HAZARDS approach. And, each of the interventions selected must be submitted to rigorous evaluation as to its effectiveness, efficacy, efficiency, and benefit. After all, terrorism has and continues to result in enhanced disaster preparedness. We must move forward together.
Lastly, globalisation has both fostered and facilitated terrorism. ${ }^{2}$ Terrorism has been fueled by the release of news bulletins and by newspapers, radio, television, and the rapid and uncontrolled use of the Internet. The global efforts united against terrorism represent a historical momentum. However, it should become increasingly clear from the material included in this issue that if anti-terrorism efforts focus exclusively on counter-terrorism and are not directed also to the causes of terrorism, they merely will breed new terrorism. Thus, we must strive to direct such efforts to the causes, which are multi-factorial and culturally embedded. Merely focusing on the terrorists and not on the motives that drive terrorism seems irrational and short-sighted. The gap in cultures seems very broad, and resolving the differences is a huge challenge. Belief that our values are best for all cultures is inappropriate and only further fuels actions aimed at gaining a specific view as to how humanity is best served. Seeking a single solution for all of the problems is naïve. Rather, tolerance and understanding of the differences and accepting the reasons rather than attempting to convert the perceptions seems a most prudent course. Otherwise, it is unlikely that the differences between the beliefs and practices of developing and developed worlds will be resolved. Several realistic approaches will follow in the next issue. Resolving centuries of differences in a few years will not happen. We must listen and try to understand. Rather than fight perceptions that do not agree with our own, we must try to understand them and the reasons they are held, and try to educate rather than to condemn. Medicine is in a unique position to facilitate the development of understanding. Fighting misunderstanding and prejudice falls within our areas of responsibility, and we no longer can ignore our role.

Always it comes about that the beginning of wisdom is fear. Miguel de Unamuno, Tragic Sense of Life, p 107

\section{References}

1. Thompson D: The Concise Oxford Dictionary of Current English. Claendon Press: Oxford. 1995. p 687
2. Task Force on Quality Control of Disaster Management: Health disaster management: Guidelines for evaluation and research in the Utstein style. Prebosp Disast Med 2002;17(suppl 3). 